\title{
Anemia is a Prognostic Factor for Overall Survival Rate in Patients with Non-Small Cell Lung Cancer Treated with Stereotactic Body Radiation Therapy
}

\author{
Hidekazu Tanaka' \\ Taiki Ono' \\ Yuki Manabe' \\ Miki Kajima' \\ Koya Fujimoto' \\ Yuki Yuasa' \\ Takehiro Shiinoki (D) \\ Yoshikazu Yamaji (D) ${ }^{2}$ \\ Kazuto Matsunaga $\mathbb{D}^{2}$ \\ 'Department of Radiation Oncology, \\ Yamaguchi University Graduate School of \\ Medicine, Ube, Japan; ${ }^{2}$ Department of \\ Respiratory Medicine and Infectious \\ Disease, Yamaguchi University Graduate \\ School of Medicine, Ube, Japan
}

Correspondence: Hidekazu Tanaka I-I-I Minamikogushi, Ube, 755-8505, Japan

Tel +81 836222966

Fax +8I $83622247 \mid$

Email h-tanaka@yamaguchi-u.ac.jp
Purpose: Anemia has been associated with poor prognosis in patients with cancer across several cancer types. It has been identified as a prognostic factor in patients with non-small cell lung cancer (NSCLC) who have undergone surgery or chemoradiotherapy. However, there are only a few reports that have evaluated the prognostic significance of anemia in patients with NSCLC undergoing stereotactic body radiation therapy (SBRT).

Patients and Methods: A total of 77 patients were enrolled in this study. The pretreatment hemoglobin $(\mathrm{Hb})$ levels, within 2 weeks before SBRT, were available for all patients. The median age of the participants (56 men, 21 women) was 80 (range, 50-90) years. The median Hb level was 12.8 (range, 7.8-18.3) g/dL. The median follow-up period was 24 (range, 1-87) months.

Results: Local recurrence was observed in 8 (10.4\%) cases during the follow-up period. The 1 - and 2-year local control (LC) rates were $94.8 \%$ and $86.4 \%$, respectively. Seventeen (22.1\%) patients died during the follow-up period. The 1- and 2-year overall survival (OS) rates were $93.1 \%$ and $85.2 \%$, respectively. Univariate analysis identified anemia and body mass index as significant prognostic factors for predicting OS. On multivariate analysis, anemia was confirmed to be the only significant factor $(p=0.02469)$.

Conclusion: Our data suggest that anemia is a prognostic factor for predicting the OS rate in patients with early-stage NSCLC treated with SBRT.

Keywords: anemia, hemoglobin, non-small cell lung cancer, stereotactic body radiation therapy, stereotactic ablative body radiotherapy

\section{Introduction}

Among all cancers, lung cancer had the highest estimated incidence and mortality rates in 2018 worldwide. ${ }^{1}$ An estimated 2,094,000 people worldwide were diagnosed with lung cancer in 2018, resulting in 1,761,000 deaths. Stereotactic body radiation therapy (SBRT) is an important treatment option for early-stage non-small cell lung cancer (NSCLC) with results comparable to surgery. ${ }^{2}$ Nagata et al reported favorable outcomes in both operable and inoperable NSCLC cases treated by SBRT. $^{3}$ Chang et al reported good results of SBRT in a pooled analysis of patients enrolled in two phase-III trials that compared surgery with SBRT. ${ }^{4}$

Anemia has been associated with a poor prognosis in patients with cancer across various types of cancer. ${ }^{5-10}$ In patients with NSCLC who undergo surgery. ${ }^{11-13}$ or radiation therapy or chemoradiotherapy, ${ }^{14-17}$ anemia has been reported as a poor prognostic factor. However, there is limited literature available on the prognostic 
significance of anemia in patients with NSCLC undergoing SBRT. ${ }^{18,19}$ The purpose of this study was to evaluate the association between pre-treatment anemia and prognosis in patients with NSCLC treated with SBRT.

\section{Materials and Methods}

\section{Patients}

This retrospective study was conducted with the approval of institutional review board of Yamaguchi University Hospital, and all patients provided written informed consent before treatment. This study was conducted in accordance with the Declaration of Helsinki.

The inclusion criteria were as follows: patients with localized NSCLC, NOM0 disease, who were clinically inoperable or refused surgery, and were treated with SBRT, and for whom the hemoglobin $(\mathrm{Hb})$ levels were available within 2 weeks before SBRT. Between September 2009 and September 2019, 77 patients meeting the inclusion criteria were identified and included in the study. Cases where the pathological diagnosis could not be confirmed were treated as NSCLC if the joint conference of respiratory surgeons, pulmonologists, radiologists, and radiation oncologists came to that consensus.

\section{Planning and Irradiation}

Before radiation treatment planning, patients were evaluated by four-dimensional computed tomography (4DCT) using Somatom (SIEMENS, Germany) for the amount of movement of the tumor caused by respiration. For 4DCT, real-time positioning management (RPM) system (Varian Medical Systems, USA) was used. Patients with respiratory motion of the tumor $\geq 1.0 \mathrm{~cm}$ were planned for the implantation of a fiducial marker which were implanted by bronchoscopy near the tumor. For every such patient, three markers were implanted.

All patients underwent $\mathrm{CT}$ scan under light exhalation breath-hold, and 4DCT were also performed using RPM. The slice thickness was 1.0 or $2.0 \mathrm{~mm}$. Patients were immobilized using Vac-Loc Cushion (CIVCO Medical Solution, USA) with both their arms up. The clinical target volume (CTV) was defined as equal to the gross tumor volume (GTV). In patients with implanted fiducial markers, the internal target volume (ITV) was equal to the CTV. In contrast, summation of the GTVs defined at every respiratory phase of the 4DCT gave the ITV in patients without the fiducial marker. The planning target volume (PTV) was generated by adding $5 \mathrm{~mm}$ around the ITV. In principle, the prescribed dose for peripherally situated tumors was 50 Gy in 5 fractions until September 2016 and 48 Gy in 4 fractions after October 2016. The tumors with a central location near organs at risk were treated with $60 \mathrm{~Gy}$ in 8 fractions. A central tumor was defined as a tumor whose distance from the proximal bronchial tree was $\leq 2 \mathrm{~cm}$. The dose was prescribed to the isocenter. Leaf margins were modified to cover the PTV by $80 \%$ of the prescribed dose. The linear accelerator used was MHCL15DP (Mitsubishi Electronics, Japan) until September 2015, and TrueBeam (Varian Medical Systems, USA) after October 2015. Treatment planning used of 6-8 beams, including 4-6 non-coplanar beams.

The treatment for patients with implanted fiducial markers was performed under motion tracking using a realtime tumor tracking system (Mitsubishi Electronics, Japan) until September 2015 and SyncTraX (Shimadzu Corporation, Japan) after October 2015. In brief, the system consists of two sets of X-ray tubes under the floor and image intensifiers on the ceiling. The fiducial marker implanted near the tumor is easily visible on the radiograph and is tracked in real time. The position of the marker is recognized as a surrogate of the tumor position. The treatment beam turns on only when the marker is located within designated area. The detailed method has been described in literature earlier. ${ }^{20}$

The treatment for patients without fiducial marker was performed under light-free breathing.

\section{Evaluation}

The medical charts were reviewed and data pertaining to age, sex, performance status (PS), body mass index (BMI), operability, smoking history (current or past vs never smoker), the presence of diabetes mellitus (DM), the presence of pathological or cytological confirmation, tumor diameter, irradiation method (respiratory gated or not), and pretreatment $\mathrm{Hb}$ levels were obtained.

The World Health Organization defines BMI $<18.5$ as underweight ${ }^{21}$ Base on the BMI $\left(\mathrm{kg} / \mathrm{m}^{2}\right.$ ) (calculated as follows: body weight $\left.(\mathrm{kg}) /[\text { height }(\mathrm{m})]^{2}\right)$, the patients were classified into two groups (BMI $<18.5$ and $\geq 18.5$ ).

The survival periods were calculated from the completion of the SBRT.

The associations between $\mathrm{Hb}$ levels and other categorical variables were tested using Mann-Whitney $U$-test and the correlation with continuous variables was tested by Spearman's rank correlation coefficient. Local control (LC) and overall survival (OS) rates were calculated using the 
Kaplan-Meier method, and group comparisons were made using the Log rank test. Univariate and multivariate Cox proportional hazard regression models were used to estimate the LC and OS rates. Variables for which the $p$-values were $<0.10$ in the univariate analysis were included in the multivariate analysis. Receiver-operating characteristic (ROC) analysis was performed to determine the optimal cut-off values for the pretreatment $\mathrm{Hb}$ level. A p-value $<0.05$ was considered to indicate a statistically significant difference.

\section{Results}

The patient characteristics are shown in Table 1. The median age of the 77 participants (56 men, 21 women) was 80 (range, 50-90) years. Most of the patients presented with a PS of 0 or $1(\mathrm{n}=71,92.2 \%)$. The median BMI was 21.5 (range, 13.1-37.3) $\mathrm{kg} / \mathrm{m}^{2}$. The median diameter of the tumor was 19 (range, 7-40) $\mathrm{mm}$. More than half of the patients had a history of smoking ( $\mathrm{n}=57,74.0 \%)$. The number of patients with a pathological confirmation of the diagnosis of NSCLC was 35 (45.4\%). The number of patients with diabetes was $17(22.1 \%)$. The reason for choosing SBRT was either inoperability $(n=56,72.7 \%)$ or refusal of surgery $(n=21,27.3 \%)$. The median $\mathrm{Hb}$ level was 12.8 (range, 7.8-18.3) g/dL.

The association between $\mathrm{Hb}$ levels and other parameters is shown in Table 2. The Hb levels were significantly lower in patients with lower BMI than in patients with a higher BMI. There was a weak positive correlation

Table I Patients' Characteristics $(\mathrm{N}=77)$

\begin{tabular}{|l|c|}
\hline Parameters & Median (Range) \\
\hline Age (years) & $80(50-90)$ \\
Sex (male/ female) & $56(72.7 \%) / 2 \mid(27.3 \%)$ \\
PS $(0 / \mathrm{I} / 2 / 3)$ & $21.5(13.1-37.3)$ \\
BMI (kg/m $\left.{ }^{2}\right)$ & $23(29.9 \%) / 54(70.1 \%)$ \\
$(<18.5 / \geq \mid 8.5)$ & $21(27.3 \%) / 51(66.2 \%)$ \\
Operability (yes/no) & $57(74.0 \%) / 20(26.0 \%)$ \\
Smoking history (yes/no) & $17(22.1 \%) / 60(77.9 \%)$ \\
DM (yes/no) & $35(45.5 \%) / 42(54.5 \%)$ \\
Pathology (confirmed/unknown) & $19(7-40)$ \\
Tumor diameter (mm) & $58(75.3 \%) / 19(24.7 \%)$ \\
Irradiation (gating/non-gating) & $12.8(7.8-18.3)$ \\
Pretreatment Hb (g/dL) & \\
\hline Prescribed dose & $50(64.9 \%)$ \\
48 Gy in 4 fractions & $23(29.9 \%)$ \\
50 Gy in 5 fractions & $4(5.2 \%)$ \\
60 Gy in 8 fractions & $24(1-87)$ \\
Follow-up periods (months) & $4.3 \%)$ \\
\hline
\end{tabular}

Abbreviations: PS, performance status; BMI, body mass index; DM, diabetes mellitus; Hb, hemoglobin. between $\mathrm{Hb}$ level and $\mathrm{BMI}$. Also, the $\mathrm{Hb}$ levels were significantly higher in patients with a smoking history than in those without a smoking history. There was no significant correlation observed between $\mathrm{Hb}$ levels and the other parameters.

The median follow-up period was 24 (range, 1-87) months. Local recurrence was observed in $8(10.4 \%)$ cases during the follow-up period. The 1- and 2-year LC rates were $94.8 \%$ and $86.4 \%$, respectively. In univariate analysis, there was no significant prognostic value of the LC rate (Table 3 ).

Seventeen $(22.1 \%)$ patients died during the follow-up period with 7 of them dying from lung cancer. The 1- and 2-year OS rates were $93.1 \%$ and $85.2 \%$, respectively. Univariate analysis found anemia and BMI as significant factors for predicting the OS rates. Multivariate analysis confirmed anemia as the only significant independent prognostic factor $(p=0.02469)$ (Table 4$)$. The optimal cut-off value of $\mathrm{Hb}$ level, as determined by ROC analysis, was 11.6 $\mathrm{g} / \mathrm{dL}$. The OS rates with lower $\mathrm{Hb}$ level were significantly poor than those with higher $\mathrm{Hb}$ level $(\mathrm{p}=0.00767)$ (Figure 1). The 1- and 2-year OS rates for higher and lower $\mathrm{Hb}$ groups were $96.1 \%$ and $88.3 \%$, and $84.4 \%$ and $76.0 \%$, respectively.

\section{Discussion}

There was a weak positive correlation between $\mathrm{Hb}$ level and BMI. $\mathrm{Hb}$ levels in patients with lower BMI were significantly lower than in the group with higher BMI. This is explained by the fact that $\mathrm{Hb}$ level is correlated with nutritional status. That is, patients with poor nutrition had low $\mathrm{Hb}$ levels and low BMI. Hb levels were significantly higher in patients with smoking history than in those without smoking history. This was because most smokers were men. In fact, men (92.5\%) had a significantly higher smoking history than women $(40.0 \%)$ (Fisher's exact test, $p=0.00000735)$. Median pretreatment $\mathrm{Hb}$ levels in men and women were 13.1 (range, 8.9-18.3) and 11.4 (range, 7.8-14.6) g/dL, respectively. Because men had significantly higher $\mathrm{Hb}$ levels than women $(\mathrm{p}=0.0187)$, and most smokers were men, smoking history could not be directly correlated with elevation of $\mathrm{Hb}$ levels.

In the recent years, there have been many reports indicating that pretreatment $\mathrm{Hb}$ levels significantly correlate with the outcomes in several types of cancer. ${ }^{5-10}$ These reports include various treatment modalities, such as surgery, chemotherapy, radiation therapy, and combination of them. Though various 
Table 2 Association Between $\mathrm{Hb}$ and Other Parameters

\begin{tabular}{|c|c|c|c|}
\hline Categorical Variables & & $p$-value & \\
\hline & $\begin{array}{l}\text { Age (<80 vs } \geq 80) \text { (years) } \\
\text { Sex (male vs female) } \\
\text { PS }(0 \text { vs } \geq 1 \text { ) } \\
\text { BMI (<18.5 vs } \geq 18.5)(\mathrm{kg} / \mathrm{m} 2) \\
\text { Operability (yes vs no) } \\
\text { Smoking history (yes vs no) } \\
\text { DM (yes vs no) } \\
\text { Pathology (confirmed or unknown) } \\
\text { Tumor diameter (<20 vs } \geq 20 \text { ) (mm) } \\
\text { Irradiation (gating vs non-gating) }\end{array}$ & $\begin{array}{c}0.363 \\
0.0187 \\
0.527 \\
0.00974 \\
0.655 \\
0.00000735 \\
0.854 \\
0.0677 \\
0.347 \\
0.0752\end{array}$ & \\
\hline \multirow[t]{2}{*}{ Continuous Variables } & & $p$-value & $\rho$ \\
\hline & $\begin{array}{l}\text { Age (years) } \\
\text { BMI }(\mathrm{kg} / \mathrm{m} 2) \\
\text { Tumor diameter }(\mathrm{mm})\end{array}$ & $\begin{array}{l}0.124 \\
0.046 \\
0.476\end{array}$ & $\begin{array}{c}-0.177 \\
0.228 \\
-0.0824\end{array}$ \\
\hline
\end{tabular}

Abbreviations: Hb, hemoglobin; PS, performance status; BMI, body mass index; DM, diabetes mellitus.

Table 3 The Results of Univariate Analysis for Local Control Rate

\begin{tabular}{|c|c|c|c|}
\hline \multicolumn{2}{|l|}{ Variables } & \multicolumn{2}{|c|}{ Local Control Rate } \\
\hline & & \multicolumn{2}{|c|}{ Univariate } \\
\hline & & Hazard Ratio $(95 \% \mathrm{CI})$ & p value \\
\hline Age (years) & Continuous & $0.9994(0.9132-1.094)$ & 0.9891 \\
\hline Sex & Male vs female & $1.883(0.2306-15.38)$ & 0.5547 \\
\hline PS & $0 \mathrm{vs} \geq 1$ & $1.700(0.4053-7.134)$ & $0.468 I$ \\
\hline BMI $\left(\mathrm{kg} / \mathrm{m}^{2}\right)$ & $18.5<$ vs $\geq 18.5$ & $2.974(0.7009-12.48)$ & 0.1363 \\
\hline Operability & Yes vs No & $0.9538(0.1917-4.745)$ & 0.9539 \\
\hline Smoking history & Yes vs No & $1.413(0.1721-11.61)$ & 0.7474 \\
\hline DM & Yes vs No & $1.166(0.3765-3.610)$ & 0.7902 \\
\hline Pathology & Confirmed vs unknown & $0.4003(0.09509-1.685)$ & 0.2219 \\
\hline Tumor diameter (mm) & Continuous & $1.035(0.9517-1.126)$ & 0.4218 \\
\hline Irradiation & Gating vs non-gating & $1.971(0.2397-16.21)$ & 0.5278 \\
\hline Pretreatment $\mathrm{Hb}(\mathrm{g} / \mathrm{dL})$ & Continuous & $0.8074(0.5282-1.234)$ & 0.3230 \\
\hline
\end{tabular}

Abbreviations: $\mathrm{Cl}$, confidence interval; PS, performance status; BMI, body mass index; DM, diabetes mellitus; Hb, hemoglobin.

Table 4 The Results of Univariate and Multivariate Analysis for Overall Survival Rate

\begin{tabular}{|c|c|c|c|c|c|}
\hline \multicolumn{2}{|l|}{ Variables } & \multicolumn{4}{|c|}{ Overall Survival Rate } \\
\hline & & \multicolumn{2}{|c|}{ Univariate } & \multicolumn{2}{|c|}{ Multivariate } \\
\hline & & Hazard Ratio (95\% Cl) & p value & Hazard Ratio (95\% CI) & p value \\
\hline Age (years) & Continuous & $1.032(0.9680-1.100)$ & 0.3371 & & \\
\hline Sex & Male vs female & $1.743(0.3875-7.843)$ & 0.4689 & & \\
\hline PS & 0 vs $\geq 1$ & $1.430(0.528 \mathrm{I}-3.873)$ & 0.4815 & & \\
\hline BMI $\left(\mathrm{kg} / \mathrm{m}^{2}\right)$ & $18.5<$ vs $\geq 18.5$ & $4.412(1.515-12.85)$ & 0.006483 & $2.6130(0.8546-7.9900)$ & 0.092100 \\
\hline Operability & Yes vs No & $0.8752(0.2817-2.719)$ & 0.8177 & & \\
\hline Smoking history & Yes vs No & $0.5077(0.1569-1.642)$ & 0.2577 & & \\
\hline DM & Yes vs No & $1.166(0.3765-3.610)$ & 0.7902 & & \\
\hline Pathology & Confirmed vs unknown & $0.4064(0.1519-1.087)$ & 0.07297 & $0.8924(0.3054-2.6080)$ & 0.835200 \\
\hline Tumor diameter (mm) & Continuous & $1.029(0.9684-1.093)$ & 0.3553 & & \\
\hline Irradiation & Gating vs non-gating & $0.575 \mid(0.1775-1.863)$ & 0.3563 & & \\
\hline Pretreatment $\mathrm{Hb}(\mathrm{g} / \mathrm{dL})$ & Continuous & $0.5647(0.4037-0.7900)$ & 0.0008476 & $0.5897(0.4047-0.8593)$ & 0.005974 \\
\hline
\end{tabular}

Abbreviations: $\mathrm{Cl}$, confidence interval; PS, performance status; BMI, body mass index; DM, diabetes mellitus; Hb, hemoglobin. 


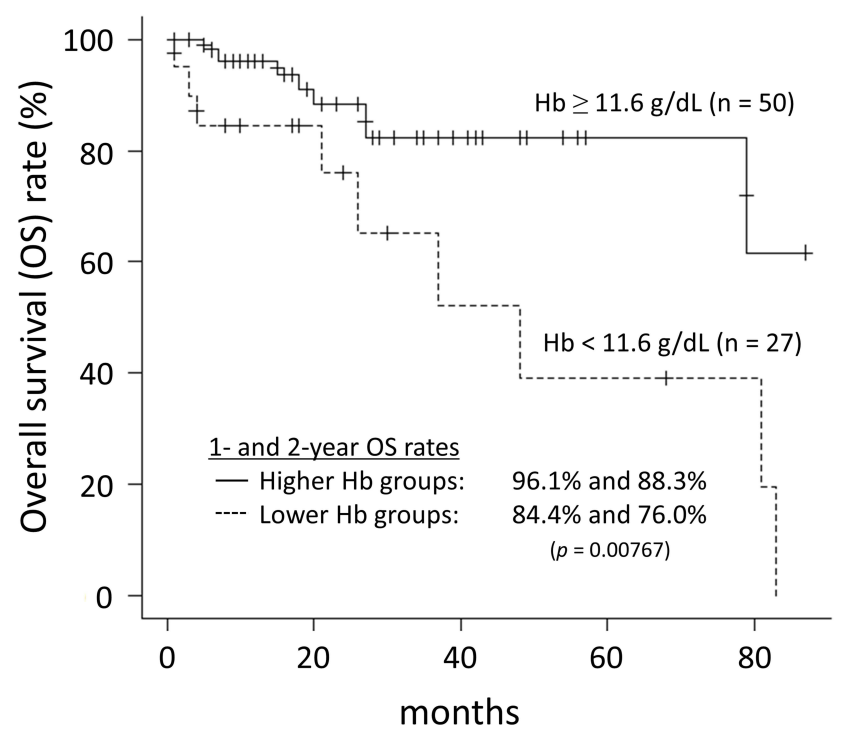

Figure I Overall survival rates for high and low hemoglobin groups.

outcome measures were reported, OS rates were most commonly reported. In patients with NSCLC, pretreatment $\mathrm{Hb}$ level was a significant predictor of prognosis in patients with treated by surgery or chemoradiotherapy ${ }^{11-17}$ However, literature about correlation between anemia and outcome in patients of NSCLC undergoing SBRT is lacking. ${ }^{18,19}$ Shaverdian et al reported that pretreatment $\mathrm{Hb}$ levels correlated significantly with OS rate and non-local disease progression, but not with LC rate. ${ }^{18}$ Their results were comparable to our results, where we found pretreatment $\mathrm{Hb}$ levels to correlate significantly with $\mathrm{OS}$ rate but not with the $\mathrm{LC}$ rate. As mentioned above, there is a significant difference in the $\mathrm{Hb}$ levels between males and females. However, since there were only 21 female enrolled patients, the relationship between $\mathrm{Hb}$ values and $\mathrm{OS}$ was analyzed for male patients only. The cutoff value for $\mathrm{Hb}$ was determined by ROC analysis, as in the case of the overall evaluation. The cutoff value for $\mathrm{Hb}$ in male patients was 12.5 $\mathrm{g} / \mathrm{dL}$. The OS in the lower $\mathrm{Hb}(<12.5 \mathrm{~g} / \mathrm{dL})$ group was significantly worse than that in the higher $\mathrm{Hb}(\geq 12.5 \mathrm{~g} / \mathrm{dL})$ group $(p=0.0227$, Log rank test) (Figure 2).

Anemia is considered to cause intratumor hypoxia. ${ }^{22}$ Because tumor hypoxia is one of the causes of radioresistance, patients with anemia are expected to have a lower LC rate post radiation therapy. However, in our results, pretreatment $\mathrm{Hb}$ levels correlated significantly with OS rate but not with the LC rate. There are a few hypotheses to explain this result. Hypoxia inducible factor (HIF) was discovered from hepatocellular carcinoma cell lines as a factor that could induce

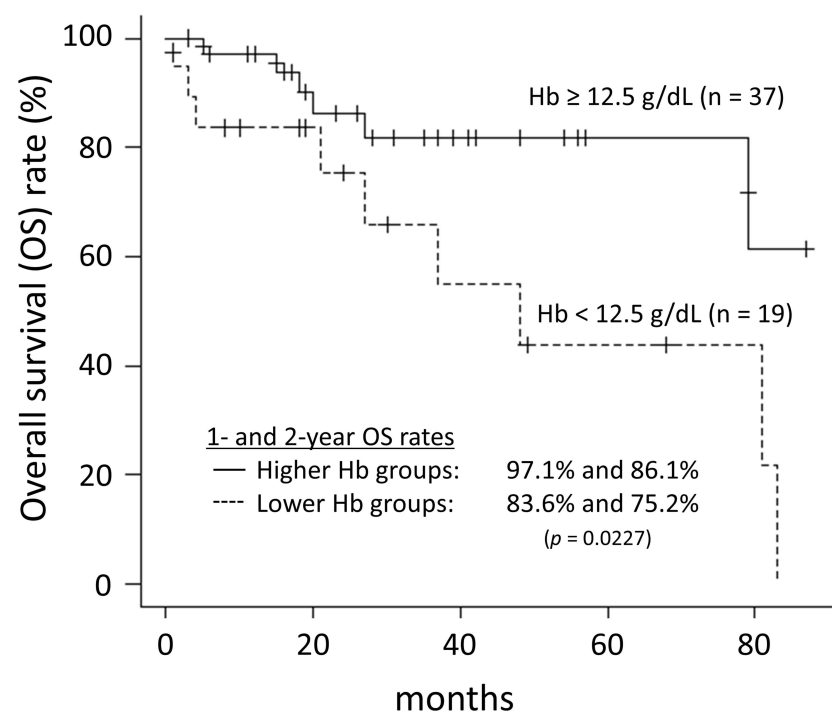

Figure 2 Overall survival rates of male patients for high and low hemoglobin groups.

hypoxia-dependent erythropoietin. ${ }^{23}$ HIF-1 induced the vascular endothelial growth factor, platelet-derived growth factor $\mathrm{B}$, and basic fibroblast growth factor, and improved hypoxia. ${ }^{24}$ In tumors, HIF-1 gets activated in response to hypoxia. ${ }^{25}$ Therefore, it cannot be concluded that the oxygen concentration in the tumor of patients with a low serum $\mathrm{Hb}$ level will be lower than that of patients with a high serum $\mathrm{Hb}$ level. Additionally, HIF causes epithelial-mesenchymal transition and also promotes metastasis. ${ }^{26}$ Hypoxia promotes tumor growth and progression to more aggressive character due to neo-angiogenesis, gene mutation, apoptosis inhibition, and free radical generation. ${ }^{22,27-29}$

SBRT is a relatively new treatment method. Many prognostic factors have been recently reported in patients with NSCLC who undergo SBRT, such as tumor size and standardized uptake value on $18 \mathrm{~F}$-fluorodeoxyglucose positron emission tomography. ${ }^{30,31}$ Pretreatment $\mathrm{Hb}$ level is an easily derived and cost-effective blood parameter. Therefore, the utility of pretreatment $\mathrm{Hb}$ as a predictive prognostic indicator is high in the clinical setting.

\section{Conclusion}

Our data suggest that anemia is correlated with OS rates in patients with early-stage NSCLC who are treated with SBRT.

\section{Disclosure}

The authors report no conflicts of interest in this work. 


\section{References}

1. GLOBOCAN 2018 [homepage on internet]. Lyon, France: International Agency for Research on Cancer, World Health Organization; [updated September, 2018; cited October 22, 2020]. Available from: http://gco.iarc. $\mathrm{fr} /$ today/onlineanalysis-multi-bars? $=2018 \&$ mode $=$ cancer\&mode $\_$popu lation $=$ countries \&population $=900 \&$ populations $=900 \&$ key $=$ asr $\&$ sex $=$ $2 \&$ cancer $=39 \&$ type $=0 \&$ statistic $=5 \&$ prevalence $=0 \&$ population_group $=$ $0 \&$ ages_group $\% 5 \mathrm{~B} \% 5 \mathrm{D}=0 \&$ ages_group $\% 5 \mathrm{~B} \% 5 \mathrm{D}=17 \mathrm{items}=$ $10 \&$ group_cancer $=1 \&$ include_nmsc $=1 \&$ include_nmsc_other=1\&type multiple $=\% 257 \mathrm{~B} \% 2522 \mathrm{inc} \% 2522 \% 253 \mathrm{Atrue} \% 252 \mathrm{C} \% 2522 \mathrm{mort} \%$ $2522 \% 253 \mathrm{Afa} 1 \mathrm{se} \% 252 \mathrm{C} \% 2522$ prev\% $2522 \% 253 \mathrm{Afa} 1 \mathrm{se} \%$ 257D\&orientation=horizontal\&type_sort $=0$ \&type_nb_items $=\% 257 \mathrm{~B} \%$ 2522 top $\% 2522 \% 253$ Atrue $\% 252 \mathrm{C} \% 2522$ bottom $\% 2522 \% 253$ Afalse $\%$ 257D\&population_group_globocan_id=. Accessed September 23, 2021.

2. NCCN Guidelinesfor treatment of cancer by site. Non-small cell lung cancer. 2020 [homepage on internet]. Pennsylvania, US: National Comprehensive Cancer Network; [updated May 21, 2020; cited October 22, 2020]. Available from: https://www.nccn.org/profes sionals/physician_gls/pdf/nscl.pdf. Accessed September 23, 2021.

3. Nagata Y, Hiraoka M, Shibata T, et al. Prospective trial of stereotactic body radiation therapy for both operable and inoperable T1N0M0 non-small cell lung cancer: Japan Clinical Oncology Group study JCOG0403. Int J Radiat Oncol Biol Phys. 2015;93(5):989-996. doi:10.1016/j.ijrobp.2015.07.2278

4. Chang JY, Senan S, Paul MA, et al. Stereotactic ablative radiotherapy versus lobectomy for operable stage I non-small-cell lung cancer: a pooled analysis of two randomized trial. Lancet Oncol. 2015;16:630-637. doi:10.1016/S1470-2045(15)70168-3

5. Dubsky P, Sevelda P, Jakesz R, et al. Anemia is a significant prognostic factor in local relapse-free survival of premenopausal breast cancer patients receiving adjuvant cyclophosphamide/methotrexate/ 5-fluorouracil chemotherapy. Clin Cancer Res. 2008;14:2082-2087. doi:10.1158/1078-0432.CCR-07-2068

6. Koulis TA, Kornaga EN, Banerjee R, et al. Anemia, leukocytosis and thrombocytosis as prognostic factor in patients with cervical cancer treated with radical chemoradiotherapy: a retrospective cohort study. Clin Transl Radiat Oncol. 2017;4:51-56. doi:10.1016/j.ctro.2017.05.001

7. Guo SS, Tang LQ, Chen QY, et al. Is hemoglobin level in patients with nasopharyngeal carcinoma still a significant prognostic factor in the era of intensity-modulated radiotherapy technology? PLoS One. 2015;10:e0136033. doi:10.1371/journal.pone.0136033

8. Väyrynen JP, Tuomist A, Väyrynen SA, et al. Preoperative anemia in colorectal cancer: relationships with tumor characteristics, systemic inflammation, and survival. Sci Rep. 2018;8:1126. doi:10.1038/ s41598-018-19572-y

9. Huang XZ, Yang YC, Chen Y, et al. Preoperative anemia or low hemoglobin predicts poor prognosis in gastric cancer patients: a meta-analysis. Dis Markers. 2019;2019:7606128.

10. Laurie SA, Jeyabalan N, Nicholas G, MacRae R, Dahrouge S. Association between anemia arising during therapy and outcomes of chemoradiation for limited small-cell lung cancer. $J$ Thorac Oncol. 2006;1:146-151. doi:10.1097/01243894-200602000-00008

11. Yovino S, Kwok Y, Krasna M, Bangalore M, Suntharalingam M. An association between preoperative anemia and decreased survival in early-stage non-small-cell lung cancer patients treated with surgery alone. Int $J$ Radiat Oncol Biol Phys. 2005;62:1438-1443. doi:10.1016/j.ijrobp.2004.12.038

12. Jazieh AR, Hussain M, Howington JA, et al. Prognostic factors in patients with surgically resected stage I and II non-small cell lung cancer. Ann Thorac Surg. 2000;70:1168-1171. doi:10.1016/S00034975(00)01529-0
13. Chamogeorgakis T, Anagnostopoulos C, Kostopanagiotou G, et al. Does anemia affect outcome after lobectomy or pneumonectomy in early stage lung cancer patients who have not received neo-adjuvant treatment. Thorac Cardiovasc Surg. 2008;56:148-153. doi:10.1055/s-2007-989455

14. Holgersson G, Sandelin M, Hoye E, et al. Swedish lung cancer radiation study group: the prospective value of anemia, thrombocytosis and leukocytosis at time of diagnosis in patients with non-small cell lung cancer. Med Oncol. 2012;29:3176-3182. doi:10.1007/ s12032-012-0247-3

15. Langendijk H, de Jong J, Wanders R, Lambin P, Slotman B. The importance pre-treatment haemoglobin level in operable non-small cell lung carcinoma treated with radical radiotherapy. Radiother Oncol. 2003;67:321-325. doi:10.1016/S0167-8140(03)00057-4

16. Pradier O, Lederer K, Hille A, et al. Concurrent low-dose cisplatin and thoracic radiotherapy in patients with in operable stage III non-small cell lung cancer: a Phase II trial with special reference to the hemoglobin level as prognostic parameter. J Cancer Res Clin Oncol. 2005;131:261-269. doi:10.1007/s00432-004-0633-0

17. Topkan E, Selek U, Ozdemir Y, et al. Chemoradiotherapy-induced hemoglobin nadir values and survival in patients with stage III non-small cell lung cancer. Lung Cancer. 2018;121:30-36. doi:10.1016/j.lungcan.2018.04.016

18. Shaverdian N, Veruttipong D, Wang J, Kupelian P, Steinberg M, Lee P. Pretreatment anemia portends poor survival and nonlocal disease progression in patients with stage I non-small cell lung cancer treated with stereotactic body radiation therapy. J Thorac Oncol. 2016;11:1319-1325. doi:10.1016/j.jtho.2016.04.030

19. Pathak RS, Pantarotto JR, Cook G, Holmes O, Cross P, MacRae RM. Anemia is a poor prognostic factor for stage I non-small cell lung cancer (NSCLC) patients treated with Stereotactic Body Radiation Therapy (SBRT). Clin Transl Radiat Oncol. 2019;16:28-33. doi:10.1016/j.ctro.2019.01.003

20. Hanazawa H, Takahashi S, Shiinoki T, et al. Clinical assessment of coiled fiducial markers as internal surrogates for hepatocellular carcinomas during gated stereotactic body radiotherapy with a real-time tumor-tracking system. Radiother Oncol. 2017;123:43-48. doi:10.1016/j.radonc.2017.02.010

21. Body mass index - BMI [homepage on internet]. Copenhagen, Denmark: World Health Organization Regional Office for Europe; [updated October 13, 2020; cited October 22, 2020]. Available from https://www.euro.who.int/en/health-topics/disease-prevention/nutrition/ a-healthy-lifestyle/body-mass-index-bmi. Accessed September 23, 2021.

22. Harrison LB, Chadha M, Hill RJ, Hu K, Shasha D. Impact of tumor hypoxia and anemia on radiation therapy outcomes. Oncologist. 2002;7:492-508. doi:10.1634/theoncologist.7-6-492

23. Semenza GL, Wang GL. A nuclear factor induced by hypoxia via de novo protein synthesis binds to the human erythropoietin gene enhancer at a site required for transcriptional activation. Mol Cell Biol. 1992;12:5447-5454.

24. Rey S, Semenza GL. Hypoxia-inducible factor-1-dependent mechanism of vascularization and vascular remodeling. Cardiovasc Res. 2010;86:236-242. doi:10.1093/cvr/cvq045

25. Brown JM, Wilson WR. Exploiting tumour hypoxia in cancer treatment. Nat Rev Cancer. 2004;4(6):437-447. doi:10.1038/nrc1367

26. Jiang J, Tang YL, Liang XH. EMT: a new vision of hypoxia promoting cancer progression. Cancer Biol Ther. 2011;11:714-723. doi:10.4161/cbt.11.8.15274

27. Varlotto J, Stevenson MA. Anemia, tumor hypoxia, and the cancer patient. Int J Radiat Oncol Biol Phys. 2005;63:25-36. doi:10.1016/j. ijrobp.2005.04.049

28. Coquelle A, Toledo F, Stern S, Bieth A, Debatisse M. A new role for hypoxia in tumor progression: induction of fragile site triggering genomic rearrangements and formation of complex DMs and HSRs. Mol Cell. 1998;2:259-265. doi:10.1016/S1097-2765(00)80137-9 
29. Dachs GU, Tozer GM. Hypoxia modulated gene expression: angiogenesis, metastasis and therapeutic exploitation. Eur $J$ Cancer. 2000;36(13):1649-1660. doi:10.1016/S0959-8049(00)00159-3

30. Matsuo Y, Shibuya K, Nagata Y, et al. Prognostic factors in stereotactic body radiotherapy for non-small- cell lung cancer. Int J Radiat Oncol Biol Phys. 2011;79:1104-1111. doi:10.1016/j.ijrobp.20 09.12 .022
31. Tanaka H, Hayashi S, Hoshi H. Pretreatment maximum standardized uptake value on 18F-fluorodeoxyglucose positron emission tomography is a predictor of outcome for stage I non-small cell lung cancer after stereotactic body radiotherapy. Asia Pac J Clin Oncol. 2016;12: e113-e117. doi:10.1111/ajco. 12128

\section{Publish your work in this journal}

Cancer Management and Research is an international, peer-reviewed open access journal focusing on cancer research and the optimal use of preventative and integrated treatment interventions to achieve improved outcomes, enhanced survival and quality of life for the cancer patient.
The manuscript management system is completely online and includes a very quick and fair peer-review system, which is all easy to use. Visit http://www.dovepress.com/testimonials.php to read real quotes from published authors. 